\title{
OP04
}

\section{COGNITIVE AND EYE MOVEMENT EFFECTS ON VIEWERS OF TEMPORAL LIGHT MODULATION FROM SOLID-STATE LIGHTING}

\author{
Jennifer Veitch
}

DOI 10.25039/x46.2019.OP04

from

CIE x046:2019

Proceedings

of the

29th CIE SESSION

Washington D.C., USA, June 14 - 22, 2019

(DOI 10.25039/x46.2019)

The paper has been presented at the 29th CIE Session, Washington D.C., USA, June 14-22, 2019. It has not been peer-reviewed by CIE.

\section{(C) CIE 2019}

All rights reserved. Unless otherwise specified, no part of this publication may be reproduced or utilized in any form or by any means, electronic or mechanical, including photocopying and microfilm, without permission in writing from CIE Central Bureau at the address below. Any mention of organizations or products does not imply endorsement by the CIE.

This paper is made available open access for individual use. However, in all other cases all rights are reserved unless explicit permission is sought from and given by the CIE.

CIE Central Bureau

Babenbergerstrasse 9

A-1010 Vienna

Austria

Tel.: +4317143187

e-mail: ciecb@cie.co.at

www.cie.co.at 


\title{
COGNITIVE AND EYE MOVEMENT EFFECTS ON VIEWERS OF TEMPORAL LIGHT MODULATION FROM SOLID-STATE LIGHTING
}

\author{
Veitch, J. A. ${ }^{1}$ \\ ${ }^{1}$ National Research Council of Canada, Ottawa, CANADA \\ jennifer.veitch@nrc-cnrc.gc.ca
}

DOI 10.25039/x46.2019.OP04

\begin{abstract}
Temporal light modulation, (TLM) of lighting systems is known to affect human visual perception, neurobiology, and performance. This experiment measured Stroop cognitive performance, reading performance, eye movements, discomfort, and phantom array perception during exposure to each of nine TLM conditions chosen to contrast conditions varying in TLM frequency, modulation depth, or duty cycle and based on predictions drawn from the IEEE S1789-2015 recommendations. Data from 50 adult participants aged 18-65 revealed small effects mostly in predicted directions. The results support the recommendation that lower modulation depths are preferable over higher, and add to our knowledge by showing that duty cycle could also influence outcomes and that the phantom array can be detected under photopic conditions. This underlies the importance of taking a lighting systems approach to studying TLM and considering a range of effects. Future research should increase statistical power by increasing task difficulty, and duration of exposure. More naturalistic viewing conditions, such as a greater range of eye and head motion, would improve the generalizability of the work.
\end{abstract}

Keywords: Stroop task; phantom array; reading; eye movements; solid-state lighting; flicker

\section{Introduction}

Compact fluorescent lamps once held great promise as a means to reduce lighting energy consumption, but market acceptance was poor. This was largely because the products did not perform as consumers expected (Sandahl et al., 2006). Among these expectancies was the belief that compact fluorescent lamps could cause health problems (Beckstead and Boyce, 1992). Such performance expectations are a key element in the decision to adopt a new technology. Users need to feel confident about the new technology in order to choose it.

Solid-state lighting (SSL) including light-emitting diodes (LEDs) risk similar problems because they can exhibit temporal light modulation (TLM) (CIE, 2017). TLM is a cyclic variation in the light output of a light source or lighting system. It may arise either because of the design of the driver or of the control system. LED products currently on the market exhibit a wide range of variability in TLM performance (Poplawski et al., 2011), and industry seeks best-practice guidance on which characteristics are to be avoided on the basis of the consequences for viewers.

There is evidence that low-frequency $(\sim 100-150 \mathrm{~Hz})$ TLM can cause adverse consequences for viewers (Wilkins, 2016). These encompass visual perceptions, cognitive performance effects, disrupted eye movements, neural activity changes, discomfort, and headache. Most research has focused on variations in the frequency or modulation depth, but there is less evidence concerning the possible effects of waveform or duty cycle.

Most investigators have chosen to focus on the visual perceptions known as temporal light artefacts (TLA) (Perz et al., 2015, Lee et al., 2017). TLAs include flicker (when the light source itself is seen to vary temporally); the stroboscopic effect (when a moving object appears to have interrupted movement), and the phantom array (when the movement of the eyes produces the appearance of a spatial pattern in the objects being viewed). TLAs are attractive research outcomes because they occur quickly, with very short exposures; however, some might argue that question whether a slightly increased probability of seeing a 
stroboscopic effect is a sufficiently adverse outcome to warrant a regulatory response. In this logic, what is missing are studies that examine TLM effects following longer exposures, and using more complex behavioural outcomes.

A few groups have looked at cognitive and behavioural outcomes (Nilsson Tengelin et al., 2017), although with complex findings. Nilsson Tengelin et al. compared various combinations of overhead and task lighting having $100 \%$ modulation depth and either $100 \mathrm{~Hz}$ or $347 \mathrm{~Hz}$ TLM, as compared to a DC condition. They found that reaction time and attention performance was somewhat better in conditions with some TLM than in the DC condition, but that conditions with TLM were more likely to cause discomfort and to give rise to stroboscopic effects when moving objects were viewed. Veitch et al. (Veitch et al., 2019) compared the effects of $0 \mathrm{~Hz}, 100 \mathrm{~Hz}$, and $500 \mathrm{~Hz}$ square-wave flicker on eye movements, pupil size, EEG activity, and cognitive task performance. The investigation found that $100 \mathrm{~Hz}$ and $500 \mathrm{~Hz}$ square-wave, $50 \%$ duty cycle, $100 \%$ modulation flicker increased arousal as compared to 0 $\mathrm{Hz}$ operation; flicker above the critical fusion frequency results in changes in brain activity. Interestingly, this arousal was accompanied by a small improvement in cognitive performance for the $500 \mathrm{~Hz}$ condition compared to the $100 \mathrm{~Hz}$ condition, which had not been expected.

One recommended practice exists to guide the lighting industry and regulators in selecting TLM conditions for lighting systems. 2015 (IEEE Power Electronics Society, 2015). The recommendation includes a formula to establish the permissible modulation depth as a function of flicker frequency (Mod\% $=0.08^{*}$ Freq). Some have argued that this is an overly conservative approach (National Electrical Manufacturers Association (NEMA) Lighting Systems Division, 2015). The experiment reported here was designed to test conditions based on the IEEE recommendations.

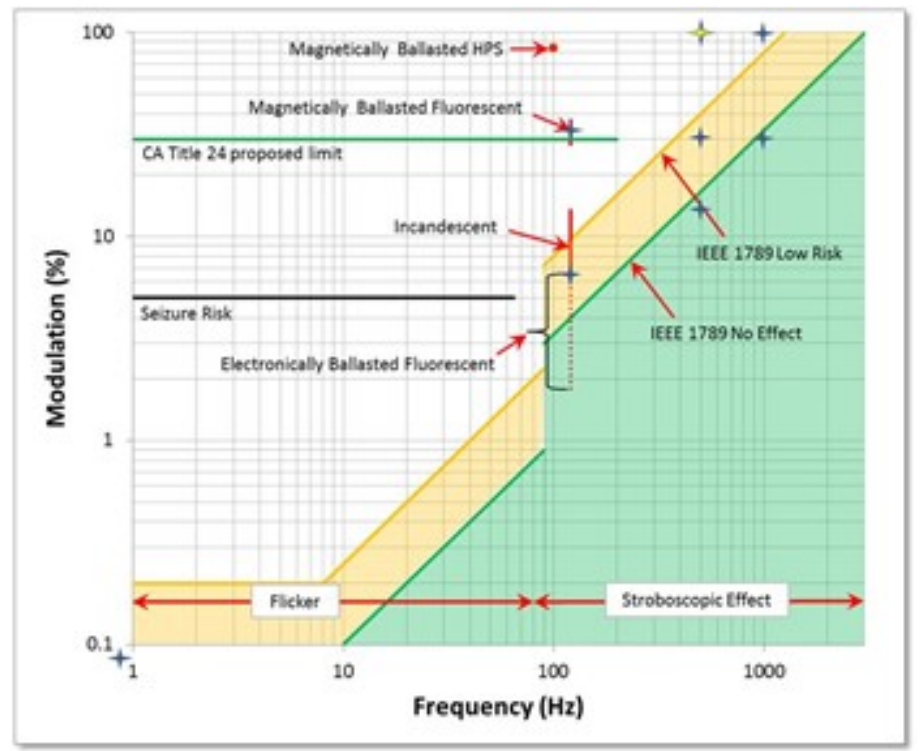

Figure 1 - Summary of experimental conditions (blue stars, and one overlaid yellow star for a duty cycle variation at $500 \mathrm{~Hz}, 100 \%$ modulation depth) tested in this experiment, against a background based on Figure 18 from IEEE S1789-2015.

Nine TLM conditions were tested, chosen to capture a range of visual conditions that would be characterized as having high risk, low risk, or no risk of adverse outcomes for viewers in the IEEE S1789 recommendations. Figure 1 shows the conditions in relation to the IEEE S1789 chart. The chart includes annotations to show the ranges for visual perception effects (horizontal red arrows), the frequency range for a high risk of epileptic seizures, and a proposed regulatory limit. The experimental conditions in this experiment are shown with blue stars, except for one variation at $500 \mathrm{~Hz}$ that involved a change in duty cycle $(50 \%$ duty cycle is blue; $30 \%$ is the yellow overlap, both at $500 \mathrm{~Hz}$ and $100 \%$ modulation depth. The blue star in the lower left is the DC condition at $0 \mathrm{~Hz}$ and $0 \%$ modulation. While viewing these conditions, participants performed a timed reading test, the Stroop test of cognitive interference, and a phantom array probe; eye movements were tracked throughout. 


\section{Method}

\subsection{Participants}

This research protocol was reviewed by the NRC Research Ethics Board to determine that it met Canadian expectations for the ethical conduct of research involving human participants. Twenty-five men and 25 women were recruited from an office temporary staffing firm for a day's participation, for which they were paid a day's wages as a clerical worker. People with either a personal or a family history of epilepsy or migraine were excluded from participation. Participants were screened for normal or corrected to normal vision and intact colour vision (Keystone View, 1969). They also completed the Wilkins and Evans Pattern Glare Test (Wilkins and Evans, 2012) to establish their risk of experiencing visual stress. Table 1 displays the key demographic characteristics. In addition, we recorded their education level, eye colour, and use of corrective lenses (30 participants needed no correction; 19 used glasses, and 1 wore contact lenses).

Table 1 - Demographic characteristics of participants

\begin{tabular}{|c|c|c|c|c|c|c|c|}
\hline \multicolumn{2}{|c|}{ Sex } & \multicolumn{5}{c|}{ Age } & Pattern Glare \\
\hline Male & Female & 18 to 29 & 30 to 39 & $40-49$ & $50-59$ & $60+$ & $>=2$ \\
\hline 25 & 25 & 17 & 11 & 8 & 10 & 4 & 4 \\
\hline
\end{tabular}

\subsection{Apparatus and lighting conditions}

The experiment took place in a small room furnished as an office (Figure 2). The general room lighting was provided by overhead fluorescent luminaires with prismatic lenses; these were $3500 \mathrm{~K}, R_{a}=80$, T8 lamps run on electronic ballasts and exhibiting minimal TLM. The room lights were controlled to match the illuminance in the light box $(\sim 400 \mathrm{Ix})$. The windows were covered with opaque blinds to eliminate variable light levels and glare from direct sun.
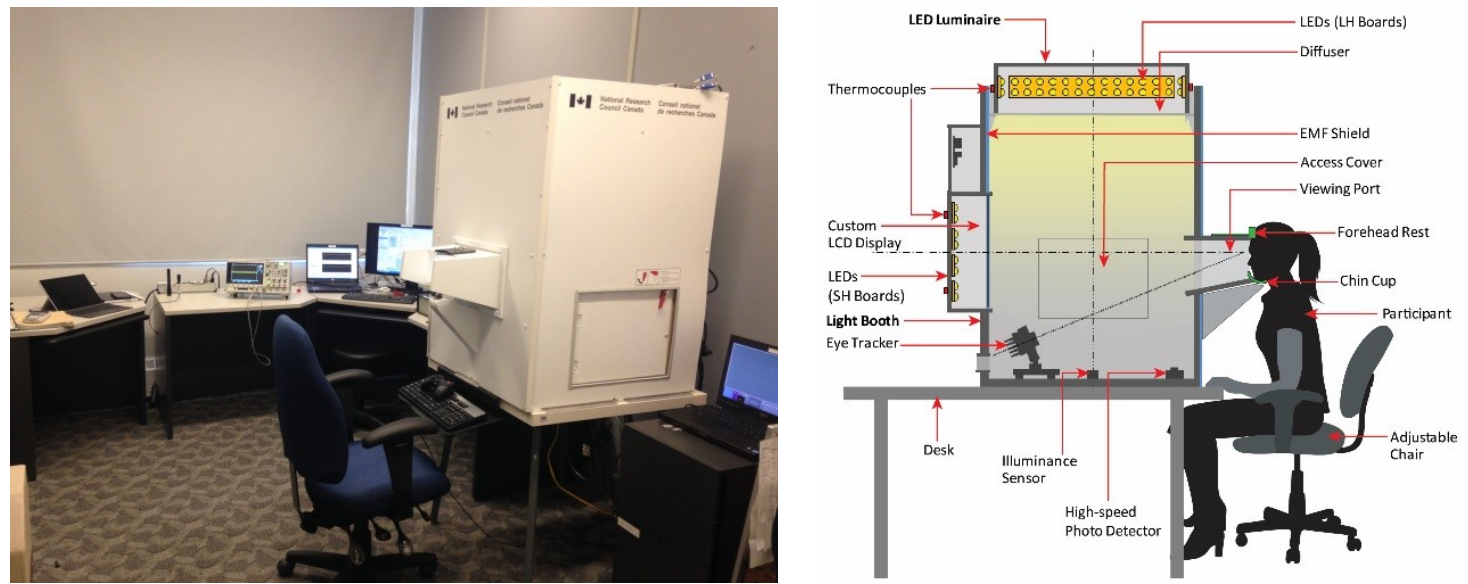

Figure 2 - The left panel shows a photograph of the experimental room (a black hood over the viewport is missing). The experimenter was seated on the right, just out of the image. The right panel shows a cutaway view of the experimental apparatus and the seated participant.

The TLM conditions were created using an Agilent programmable power supply located in the adjacent room to control noise. The power supply controlled all of the LEDs in the apparatus, both those providing the overhead light and those illuminating the LCD computer monitor. Thus, the whole visual field had the same TLM pattern. Table 2 describes the nine conditions with several important metrics. 
Table 2 - The nine experimental conditions in this experiment, characterized in terms of several TLM metrics

\begin{tabular}{|c|c|c|c|c|c|c|c|c|}
\hline Label & $\mathrm{Hz}$ & $\begin{array}{l}\text { Mod } \\
\%\end{array}$ & $\begin{array}{l}\text { Duty } \\
\text { cycle\% }\end{array}$ & Shape & Calc. FI & Meas. FI & $\begin{array}{l}\text { Meas. } \\
\mathrm{P}_{s t}{ }^{\mathrm{LM}}\end{array}$ & $\begin{array}{l}\text { Meas. } \\
\text { SVM }\end{array}$ \\
\hline TLM1 & 0 & 0 & & flat & 0 & 0,01 & 0,10 & 0,11 \\
\hline TLM2 & 120 & 6,6 & & sine & 0,02 & 0,03 & 0,09 & 0,31 \\
\hline TLM3 & 120 & 28,4 & & sine-ish & 0,07 & 0,07 & 0,10 & 0,77 \\
\hline TLM4 & 500 & 100 & 50 & square & 0,5 & 0,48 & 0,91 & 1,79 \\
\hline TLM5 & 500 & 30 & 50 & square & 0,15 & 0,13 & 0,19 & 0,49 \\
\hline TLM6 & 500 & 100 & 30 & square & 0,7 & 0,64 & 1,27 & 2,32 \\
\hline TLM7 & 500 & 15 & 50 & square & 0,08 & 0,05 & 0,08 & 0,20 \\
\hline TLM8 & 1000 & 100 & 50 & square & 0,5 & 0,45 & 0,96 & 1,34 \\
\hline TLM9 & 1000 & 30 & 50 & square & 0,15 & 0,09 & 0,21 & 0,28 \\
\hline
\end{tabular}

\subsection{Dependent measures}

\subsubsection{Reading performance}

Participants completed the Wilkins Rate of Reading Test, in which they read random words presented in blocks of 10 words per line and 15 lines (Wilkins et al., 1996). They had 1 minute to read each block aloud, and the experimenter coded both the total words read and the number of errors. The experimenter coded accuracy of the reading by scoring the task on a paper copy, but an audio recording was made to permit later verification. The test was presented in small and large print sizes (order counterbalanced per exposure block) on the video monitor in the light box with black text on a white background.

\subsubsection{Stroop task}

This is a well-established test of cognitive load (Stroop, 1935). Participants responded to one of three coloured words (RED, GREEN, BLUE) presented randomly on a white background. In congruent trials, the meaning of the word matched the colour in which it appeared on the screen. In incongruent trials, the meaning and the colour of the text did not match. For example, the word BLUE would appear in red letters. Participants pressed a key on a gamepad to indicate either the meaning of the word ("word" trials) or the colour in which it was presented ("colour" trials). Incongruent trials are more difficult than congruent ones, showing lower accuracy and slower performance; this effect becomes more pronounced under conditions of greater cognitive load.

There were 24 training trials at the start of the session, presented under DC lighting (before the exposure blocks), during which time participants learned the mapping of colours to keys on the gamepad; this was confirmed before continuing to the experimental trials. The training trials were not included in the data analysis.

In each TLM exposure block, there were 96 trials for which the instruction was to respond to the word, and 96 for which the instruction was to respond to the colour. The two dependent measures were the accuracy difference between incongruent and congruent trials, and the difference in average response speed between correct incongruent and correct congruent trials. Word and colour trials were counterbalanced across participants (but always in the same order for each participant, to avoid confusion). 


\subsubsection{Phantom array}

This is a visual perception change (TLA) induced by TLM: "change in perceived shape or spatial positions of objects, induced by a light stimulus the luminance or spectral distribution of which fluctuates with time, for a non-static observer in a static environment" (CIE 2016). This experiment was a conceptual replication of the task developed by Roberts and Wilkins (Roberts and Wilkins, 2013). Fixation dots were placed on either side of the monitor in the light box, and a vertical black line was displayed down the centre of the monitor. The participant was instructed to move their eyes back and forth from the left to right dot and back. They were to press a button on the right to report "yes" if they saw a pattern of lines while doing this, or one on the left to report "no".

\subsubsection{Comfort ratings}

At the end of each exposure block, participants rated their discomfort on a 5-point scale from 0 (no discomfort) to 4 (extreme discomfort) for the following visual experiences: Overall comfort; smarting, itchy, or aching eyes; sensitivity to light; teary eyes; dry eyes; sore back, wrists or arms; excessive fatigue; headache.

\subsubsection{Eye movements}

An Eyelink 1000 eye tracking system (SR Research, Kanata, Ontario, Canada) recorded and scored eye movements and blinks throughout the TLM exposure blocks. The system is capable of saccade resolution to 0.05 degrees of visual angle. For the reading task we examined the median across all trials by print size for the number of blinks, number of saccades taken and the median saccade velocity, and the median number of fixations and the duration of fixations, and pupil size. We also examined these eye movements during the phantom array task. For the Stroop colour and word, congruent and incongruent, trials (analysed separately) we examined only the pupil size.

\subsubsection{Lighting beliefs and expectancies}

At the end of the session, participants completed a 32-item questionnaire concerning the effects that people believe that lighting has on them (Veitch and Gifford, 1996). After reversecoding the negatively-worded items, the total score is the average of answers on all 32 items, with higher scores indicating stronger beliefs that lighting affects one's health and behaviour. The questions were presented on the monitor in the light box, under TLM1 (DC), followed by three open-ended questions concerning their beliefs about the purpose of the experiment.

\subsection{Procedure}

Participants arrived at 8:30 a.m., and the workday was divided into four sections with two fifteen-minute coffee breaks and one 45-min lunch break. After a brief orientation (location of the break room, washrooms, etc.), instructions, consent signing, vision screening, and the Pattern Glare Sensitivity task took place at the desk at the far end of the room. Then the participant took the seat in front of the apparatus.

The order of presentation of TLM conditions across blocks was randomized for each participant. The experimenter was not aware of the hypotheses nor aware of what changed about the lighting conditions from one condition to another. Period 1 (to the morning coffee break, taken in a windowless room) followed the introductory activities, with two blocks (two experimental conditions). Between back-to-back blocks there was always a 5-min pause during which time the participant was asked to sit back from the apparatus and to rest with eyes closed, or they could stand and stretch. Period 2 had two blocks; lunch followed (taken either in the break room or in a cafeteria in a nearby building). Period 3 had three blocks. Period 4, after the second coffee break, had two blocks and the final two questionnaires. After watching a video with debriefing information, the participant departed.

Within each block, the tasks were sequenced as follows: Eye tracker calibration; Reading font 1; Reading - font 2; drift check (for eye tracking accuracy); Stroop - mode 1; Stroop mode 2; drift check; Phantom array; Discomfort questions. The presentation of tasks and the collection of Stroop performance data, eye movements, and questionnaire variables were automated by Experiment Builder software (SR Research, Kanata, ON). Although the day had 
been planned to provide for $\sim 30$ min exposure to each condition, most participants were faster than anticipated, with the average time per block being $\sim 16$ minutes in total.

\section{Results}

\subsection{Data screening and analysis framework}

Each dependent variable was tested for normality, and consideration was given to the exclusion of outliers to improve the distributions. All cases were retained. Given that the purpose of the experiment was to create possibly extreme conditions, and to seek to identify sensitive individuals, it made best sense to keep as much data as possible. Sample sizes varied from one analysis to another because of occasional missing data.

This repeated-measures experiment with 9 TLM conditions provided 8 degrees of freedom for statistical tests. There were 8 non-orthogonal planned comparisons based on theoretical considerations, shown in Table 3 with the hypothesized outcomes. Each was a single degreeof-freedom comparison between the condition in column A and the one in column B. LS are comparisons involving light source simulated signals. MD are comparisons involving modulation depth. DUTY is a comparison involving duty cycle. FR is primarily a comparison between frequencies. Rep is a replication of prior work.

The testing model used multivariate analysis of variance (MANOVA) for separate analyses of conceptually related dependent variables: reading performance (2 dependent variables [DVs]), Stroop performance (2 DVs), and eye movements during reading (6 DVs) and eye movements during the phantom array (6 DVs). To avoid over-interpreting spurious effects, this paper includes significant univariate tests only if the parent multivariate test passed the threshold for statistical significance $(p<.05)$. Univariate analysis of variance (ANOVA) tests were used for separate analyses of eye movements during the Stroop task (1 DV, pupil size) and for the discomfort rating. Non-parametric tests were used for phantom array perception.

There were additional independent variables for the reading (print size) and Stroop (trial type [colour and word] and trial difficultly [congruent and incongruent]) tasks. Tests included all main effects and interactions in single-degree-of-freedom contrasts.

Table 3 - Planned comparisons between experimental conditions, and expected outcomes.

\begin{tabular}{|c|c|c|c|}
\hline Test & A & B & Expected Outcome \\
\hline LS1 & TLM1 & TLM2 & Probably no effect \\
\hline LS2 & TLM1 & TLM3 & Diminished performance, disrupted eye movements under TLM3 \\
\hline MD1 & TLM4 & TLM5 & $\begin{array}{l}\text { Poorer performance for TLM4 (100\% Mod.) than TLM5 (30\% } \\
\text { Mod.). }\end{array}$ \\
\hline MD2 & TLM5 & TLM7 & $30 \%$ (TLM5) vs $15 \%$ (TLM7) modulation depth, probably no effect. \\
\hline MD3 & TLM8 & TLM9 & $\begin{array}{l}\text { Poorer performance for TLM8 (100\% Mod.) than TLM9 }(30 \% \\
\text { Mod.). }\end{array}$ \\
\hline DUTY & TLM4 & TLM6 & Poorer performance for TLM6 (30 \% duty cycle) than TLM4 (50\%). \\
\hline FR & TLM3 & TLM9 & Poorer performance for TLM3 $(120 \mathrm{~Hz})$ than TLM9 $(1000 \mathrm{~Hz})$. \\
\hline REP & TLM1 & TLM4 & Replicating prior work, predicted better performance for TLM4 \\
\hline
\end{tabular}

\subsection{Task variables}

The results for these comparisons were mostly as expected, with large effects. The print size of the reading task influenced all of the eye movement variables (larger print showed more blinks, more saccades, larger saccades, more fixations and larger pupils; but shorter fixations) and the speed of reading (faster reading for larger print), but not the error rate. Stroop trial congruency influenced pupil size, with pupils enlarging during the incongruent trials; Stroop trial type (colour versus word) did not affect pupil size. The Stroop trial type (colour or word) influenced the reaction time but not the accuracy. Details of these tests are available from the author on request. 


\subsection{TLM effects on cognitive performance, eye movements, and discomfort}

Comparatively few of the planned comparisons showed statistically significant results; these are displayed in Table 4 and Figure 3 . The univariate effects were small by the established guidance for the Cohen's $d$ effect size estimate (Cohen, 1988).

Table 4 - These are the TLM comparisons that reached statistical significance.

\begin{tabular}{|c|c|c|c|c|c|c|c|}
\hline Concept & Test & DVs & $F$ & $d f$ & $p$ & Cohen's $d$ & Means (SD) \\
\hline $\begin{array}{l}\text { Stroop - } \\
\text { Eye Move. }\end{array}$ & LS1 & Pupil Size & 6,40 & 1,42 & 0,02 & 0,39 & $\begin{array}{l}\text { TLM1 } 581(148) \\
\text { TLM2 } 603(158)\end{array}$ \\
\hline $\begin{array}{l}\text { Phantom } \\
\text { Array - Eye }\end{array}$ & MD1 & $\begin{array}{l}\text { Multivariate } \\
\text { Pupil Size }\end{array}$ & $\begin{array}{l}2,60 \\
4,84\end{array}$ & $\begin{array}{l}6,37 \\
1,42\end{array}$ & $\begin{array}{l}0,03 \\
0,03\end{array}$ & 0,34 & $\begin{array}{l}\text { TLM4 } 711(209) \\
\text { TLM5 } 677 \text { (175) }\end{array}$ \\
\hline Discomfort & MD1 & $\begin{array}{l}\text { Discomfort } \\
\text { Rating }\end{array}$ & 4,51 & 1,46 & 0,04 & 0.31 & $\begin{array}{lll}\text { TLM4 } & 0,47 & (0,52) \\
\text { TLM5 } & 0,56 & (0,61)\end{array}$ \\
\hline $\begin{array}{l}\text { Reading - } \\
\text { Performance }\end{array}$ & MD3 & $\begin{array}{l}\text { Multivariate } \\
\text { Errors }\end{array}$ & $\begin{array}{l}3,23 \\
5,02\end{array}$ & $\begin{array}{l}2,45 \\
1,46\end{array}$ & $\begin{array}{l}0,05 \\
0,03\end{array}$ & 0,33 & $\begin{array}{l}\text { TLM8 } 2,58(2,19) \\
\text { TLM9 2,15 }(1,73)\end{array}$ \\
\hline $\begin{array}{l}\text { Phantom } \\
\text { Array - Eye }\end{array}$ & MD3 & Multivariate & 2,51 & 6,37 & 0,04 & & \\
\hline $\begin{array}{l}\text { Reading - } \\
\text { Performance }\end{array}$ & $\begin{array}{l}\text { DUTY* } \\
\text { Print } \\
\text { Size }\end{array}$ & $\begin{array}{l}\text { Multivariate } \\
\text { Errors }\end{array}$ & $\begin{array}{l}4,33 \\
6,34\end{array}$ & $\begin{array}{l}2,45 \\
1,46\end{array}$ & $\begin{array}{l}0,02 \\
0,02\end{array}$ & & See Figure 3 \\
\hline $\begin{array}{l}\text { Reading - } \\
\text { Performance }\end{array}$ & DUTY & $\begin{array}{l}\text { Multivariate } \\
\text { Errors }\end{array}$ & $\begin{array}{l}3,42 \\
6,99\end{array}$ & $\begin{array}{l}2,45 \\
1,46\end{array}$ & $\begin{array}{l}0,04 \\
0,01\end{array}$ & 0,39 & $\begin{array}{l}\text { TLM4 } 2,40(2,16) \\
\text { TLM6 2,09 }(1,81)\end{array}$ \\
\hline
\end{tabular}

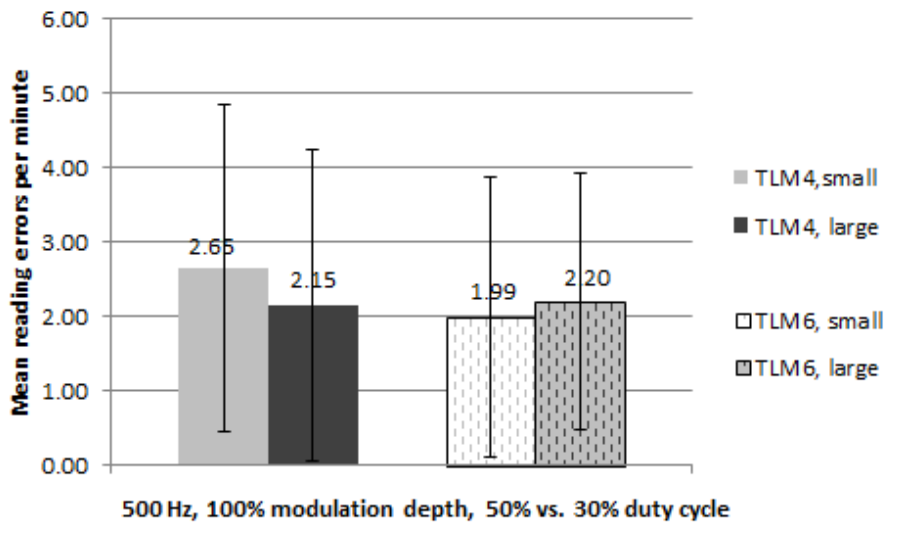

Figure 3. There was an interaction of duty cycle and print size for the DUTY planned comparison, in which the larger print improved performance for the higher duty cycle but had no effect for the lower duty cycle. The chart shows means with standard deviations.

\subsection{TLM effects on phantom array perception}

Table 5 shows the detection rate for the phantom array perception. We used the nonparametric sign test for the 8 planned comparisons between TLM conditions. This test examines whether or not individuals gave the same or different answer to the two conditions. None of these tests reached the criterion for statistical significance. We also correlated the 
corrected detection (deducting the score for TLM1, the DC condition) to the FI, Pst ${ }^{\mathrm{LM}}$, and SVM metrics for the conditions (Table 2). The nonparametric Spearman rho correlation was largest for $\mathrm{FI}$ (rho $=0,47, p=0,20)\left(\mathrm{P}_{\mathrm{st}} \mathrm{LM}\right.$ : rho $\left.=0,26, p=0,49\right)$ and SVM: rho $\left.=0,38, p=0,31\right)$, although none of these rank-order correlations $(\mathrm{N}=9)$ reached statistical significance.

Table 5 - Counts of respondents who saw (or not) the phantom array effect for each TLM condition. There was one missing case for TLM 2 and TLM 8.

\begin{tabular}{|l|l|l|l|l|l|l|l|l|l|}
\hline & TLM1 & TLM2 & TLM3 & TLM4 & TLM5 & TLM6 & TLM7 & TLM8 & TLM9 \\
\hline Yes/No & $9 / 41$ & $10 / 39$ & $11 / 39$ & $10 / 40$ & $11 / 39$ & $15 / 35$ & $13 / 37$ & $12 / 37$ & $11 / 39$ \\
\hline
\end{tabular}

\section{Discussion}

This experiment does not conclusively validate the IEEE 1789-2015 risk categories for cognitive performance, as it had been designed to do. Not all of the effects expected were found. Partly consistent results were obtained for comparisons LS1, MD1, and MD3. The DUTY comparison was opposite to expectations. LS2, FR, and REP failed to show expected results; the null result for MD2 had been expected. The one, small, effect for LS1 - larger pupils under the simulated incandescent TLM, suggesting a slight increase in arousal (Kahneman et al., 1968) - was unexpected, and difficult to interpret given the absence of effects for comparisons of larger TLM variations.

The modulation depth effects were largely as expected, with generally better outcomes for $30 \%$ modulation depth in comparison to $100 \%$ at both $500 \mathrm{~Hz}$ (smaller pupil size during phantom array) and $1000 \mathrm{~Hz}$ (fewer reading errors). However, there was an unexpected result: visual discomfort was lower for $100 \%$ modulation depth than for $30 \%$ at $500 \mathrm{~Hz}$.

There is little data on the effects of varying duty cycle; this experiment found that a lower duty cycle $(30 \%)$ decreased reading errors compared to a higher duty cycle (50\%). Duty cycle interacted with task difficulty (increasing print size). This underlies the importance of taking a lighting systems approach to studying TLM, because the issues may also arise from dimming rather than only from the light source driver.

To our knowledge this is the first experiment to demonstrate the phantom array effect at photopic light levels when the array itself is not luminous (a black line on a luminous white background). Detection of the phantom array showed the best correlation to the IES flicker index. This is worthy of further exploration, particularly under less-restrictive viewing conditions with greater eye and head movement.

TLM research consistently shows small effects in the general population (e.g., Veitch and Newsham, 1998), and this experiment is no exception. Future research should increase statistical power with larger sample sizes, longer exposures, and a focus on more difficult tasks that increase visual and cognitive demands, as these appear to be more sensitive. A focus on sensitive populations might also provide stronger evidence of the effects of TLM as well as an indication of the risks to be avoided. Further analyses of the data reported here to focus on those with high pattern glare sensitivity are planned as a first step in that direction.

\section{References}

BECKSTEAD, J. W. \& BOYCE, P. R. 1992. Structural equation modeling in lighting research: An application to residential acceptance of new fluorescent lighting. Lighting Research and Technology, 24, 189-201.

COHEN, J. 1988. Statistical power analysis for the behavioral sciences, Hillsdale, NJ, Erlbaum.

CIE 2016. CIE TN006:2016. Visual aspects of time-modulated lighting systems - Definitions and measurement models. Vienna, Austria: CIE. 
CIE 2017. CIE TN 008:2017. Final report CIE stakeholder workshop for temporal light modulation standards for lighting systems. Vienna, Austria: CIE.

DILAURA, D. L., HOUSER, K. W., MISTRICK, R. G. \& STEFFY, G. R. 2011. The lighting handbook, New York, Illuminating Engineering Society of North America.

IEEE POWER ELECTRONICS SOCIETY 2015. IEEE S1789-2015. IEEE recommended practices for modulating current in high-brightness LEDs for mitigating health risks to viewers. New York, NY: Institute for Electrical and Electronics Engineers, Inc. (IEEE).

INTERNATIONAL ELECTROTECHNICAL COMMISSION (IEC) 2017. IEC TR 61547-1:2017. Equipment for general lighting purposes - EMC immunity requirements - Part 1: An objective light flickermeter and voltage fluctuation immunity test method. Geneva, Switzerland: IEC.

INTERNATIONAL ELECTROTECHNICAL COMMISSION (IEC) 2018. IEC TR 63158:2018. Equipment for general lighting purposes - Objective test method for stroboscopic effects of lighting equipment. Geneva, Switzerland: IEC.

KAHNEMAN, D., PEAVLER, W. S. \& ONUSKA, L. 1968. Effects of verbalization and incentive on the pupil response to mental activity. Canadian Journal of Psychology, 22, 186-196.

LEE, C. S., LEE, J. H., PAK, H., PARK, S. W. \& SONG, D. W. 2017. Phantom array and stroboscopic effects of a time-modulated moving light source during saccadic eye movement. Lighting Research \& Technology, 50, 772-786.

NATIONAL ELECTRICAL MANUFACTURERS ASSOCIATION (NEMA) LIGHTING SYSTEMS DIVISION 2015. Temporal light artifacts (flicker and stroboscopic effects). Rosslyn, VA: National Electrical Manufacturers Association.

NILSSON TENGELIN, M., KÄLLBERG, S. \& JARLEMARK, P. 2017. Efffects of non-visual optical flicker in an office with two different light sources. Proceedings of the Conference "Smarter Lighting for Better Life" at the CIE Midterm Meeting 2017, October 23-25, 2017, Jeju, South Korea. Vienna, Austria: CIE.

PERZ, M., VOGELS, I. M. L. C., SEKULOVSKI, D., WANG, L. L., TU, Y. \& HEYNDERICKX, I. E. J. 2015. Modeling the visibility of the stroboscopic effect occurring in temporally modulated light systems. Lighting Research and Technology, 47, 281-300.

POPLAWSKI, M. E., DIXON, B. C., RUSSELL, B. W. \& PAGET, M. L. 2011. Exploring flicker in SSL integral replacement lamps. Richland, WA: Pacific Northwest National Laboratory.

ROBERTS, J. E. \& WILKINS, A. J. 2013. Flicker can be perceived during saccades at frequencies in excess of $1 \mathrm{kHz}$. Lighting Research and Technology, 45, 124-132.

SANDAHL, L. J., GILBRIDE, T. L., LEDBETTER, M. R., STEWARD, H. E. \& CALWELL, C. 2006. Compact fluorescent lighting in America: Lessons learned on the way to market. Richland, WA: Pacific Northwest National Laboratory.

STROOP, J. R. 1935. Studies of interference in serial verbal reactions. Journal of Experimental Psychology, 18, 643-662.

VEITCH, J. A. \& GIFFORD, R. 1996. Assessing beliefs about lighting effects on health, performance, mood, and social behavior. Environment \& Behavior, 28, 446-470.

VEITCH, J. A. \& NEWSHAM, G. R. 1998. Lighting quality and energy-efficiency effects on task performance, mood, health, satisfaction and comfort. Journal of the Illuminating Engineering Society, 27, 107-129.

VEITCH, J. A., VAN ROON, P., D'ANGIULLI, A., WILKINS, A. J., LEHMAN, B., BURNS, G. J. \& DIKEL, E. E. 2019. Effects of luminous modulation on cognitive performance, eye movements, and brain function. Manuscript in preparation.

WILKINS, A. J. 2016. A physiological basis for visual discomfort: Application in lighting design. Lighting Research and Technology, 48, 44-54.

WILKINS, A. J. \& EVANS, B. J. W. 2012. I.O.O. Pattern Glare Test, London, UK, i.O.O Sales Ltd. 
WILKINS, A. J., JEANES, R. J., PUMFREY, P. D. \& LASKIER, M. 1996. Rate of reading test: Its reliability, and its validity in the assessment of the effects of coloured overlays. Ophthalmic and Physiological Optics, 16, 491-497.

\section{Acknowledgements}

This report is a product of the NRC project A1-008878, Solid-State Lighting Flicker: Effects on Viewers, which is part of the NRC High Performance Buildings program. Financial support was provided by the Jim $\mathrm{H}$. McClung Foundation for Lighting Research, the Independent Electricity System Operator Conservation Fund (Province of Ontario), and the National Research Council of Canada. The author thanks Erhan Dikel, Brad Gover, Steve Kruithof, Sandra Mancini, Trevor Nightingale, and Meng Qi (Nikki) Zhang at NRC Construction for their contributions and support; and Tess Perrin, Michael Poplawski, Naomi Miller (Pacific Northwest National Laboratory), Steve Coyne (Light Naturally, Australia) and Arnold Wilkins (University of Essex) for advice and assistance.

(c) 2019, Her Majesty the Queen in Right of Canada. National Research Council of Canada. 